\title{
Considerações sobre as políticas públicas de apoio à economia solidária em Londrina: o desafio da comercialização
}

\author{
Considerations on public supportive policies concerning the solidary economy in Londrina: \\ the marketing challenge
}

\author{
Benilson Borinelli* \\ Luis Miguel Luzio dos Santos** \\ Sinival Osório Pitaguari ${ }^{* * *}$
}

\begin{abstract}
Resumo:
Este artigo apresenta algumas questões constatadas na operacionalização de um projeto de extensão universitária (PROSOL) da Universidade Estadual de Londrina, cujo objetivo é montar uma rede de apoio à comercialização de produtos de socioeconomia de grupos de produção incubados pelo Centro Público de Economia Solidária de Londrina (CPES). Os dados deste estudo exploratório foram levantados em documentos e na observação direta de acontecimentos. A análise centra-se em um evento de produção, a "Operação Colomba Solidária", na implementação da política pública de Economia Solidária (ES) e nos perfis dos produtos e proposta de novas áreas de atuação para a ES em Londrina. O trabalho lança luz sobre o universo, as possibilidades e os limites para a criação de novos arranjos institucionais e tecnológicos para a viabilização da comercialização de produtos de ES.
\end{abstract}

Palavras-chave: Economia Solidária; Política Pública; Comercialização; Tecnologia Social; Londrina.

\begin{abstract}
:
This article presents some issues observed in the operationalization of a university project for the community (PROSOL) of the State University of Londrina, whose purpose is to set up a supportive network for the marketing of socioeco nomy products manufactured by production groups incubated by the Solidary Economy Public Center of Londrina (CPES). The data from this exploratory study were obtained from documents and direct observation of happenings. The analysis is centered in a production event, the "Operação Colomba Solidária" (Solidary Colomba Operation), in the implementation of the public policy of Solidary Economy (ES) as well as in the profiles of products and proposal of new areas of operation for the SE in Londrina. This work throws some light on the universe, the possibilities and limits for the creation of new institutional and technological arrangements for the marketing feasibility of Solidary Economy products.
\end{abstract}

Key words: Solidary Economy; Public Policy; Marketing; Social Technology; Londrina.

\footnotetext{
* Universidade Estadual de Londrina - Doutor em Ciências Sociais. Email: benilson@uel.br

** Universidade Estadual de Londrina. Doutor em Ciências Sociais. Email: Imig@uol.com.br

*** Universidade Estadual de Londrina - Mestrando em Economia Regional na Universidade Estadual de Londrina. Email: sinival@uel.br
} 


\section{Introdução}

Londrina é um município pólo regional localizado no norte do Paraná, cuja origem esteve ligada a expansão da economia cafeeira na década de 20 do século passado, o que contribuiu para que a cidade crescesse muito rapidament e, chegando a atingir hoje, aproximadamente, meio milhão de habitantes e possuir uma diversificada rede de serviços comerciais e financeiros, agroindústrias, escolas, universidades, modernos hospitais e etc. Porém, Londrina sofreu muito com o êxodo rural $\mathrm{n}$ a região, provocado pela crise de erradicação do café e a conseqüente diversificação e mecanização da agricultura na segunda metade da década de 1970. Foi prejudicada também pela crise econômica nacional nos anos de 1980 e 1990. A consequência foi o surgim ento de inúmeras habitações irregulares e um alto índice de desemprego. Apesar da recuperação obtida na última década, o percentual de pobreza das famílias londrinenses é de 7,59\% (11.115 famílias). (LONDRINA, 2008)

Em resposta a esse contexto de exclusão social e de falta de alternativas, desenvolveu-se na Universidade Estadual de Londrina (UEL), em parceria com o Centro Público de Economia Solidária de Londrina e a Incubadora Tecnológica de Empreendimentos Solidários (INTES), um projeto de extensão denom inado Rede de Comercialização e Apoio a Produtos e Serviços de Organizações de Socioeconomia (PROSOL). Ele possui como objetivo geral a concepção e a operacionalização de uma rede de comercialização e apoio a produtos e serviços de organizações de socioeco nomia da região de Londrina. Para a execução dessa tarefa, foram traçadas, inicialmente, duas metas básicas. A primeira concentra-se no levantamento de experiências de redes de comercialização no município, em outras cidades e países. A segunda meta fundam entase na criação e operacionalização da rede.

Integraram o projeto professores, recém -formados e graduandos dos cursos de Administração, Ciências Econômicas e Serviço Social, todos atuantes na UEL. A duração do PROSOL foi de 12 meses, com início em deze mbro de 2008 e término em novembro de 2009. Este artigo é uma análise dos primeiros seis meses do projeto.

Ainda que o período analisado seja curto, alguns conflitos e questões deixam clara a complexidade de trabalhar em ambientes que se almejam democrátic os e economicamente viáveis, o que pôde ser sentido nos embates institucionais, decorrentes 
das diferentes culturas, percepções, interesses e até mesmo concepções do que vem a ser ES. Os conflitos acirraram -se no grau de concessões entendidas como necessár ias para que ao mesmo tempo se preservem os princípios da ES e se viabilizem as iniciativas dentro do mercado capitalista.

Para o desenvolvimento do artigo foram utilizados dados coletados em relatórios de atividades do PROSOL e do CPES e na observação di reta de acontecimentos em reuniões de planejamento e avaliação com técnicos da prefeitura e membros de 20 grupos de produção incubados pelos CPES, bem com da participação direta dos autores no desenvolvimento de atividades coletivas, como a operação "Colom ba Pascal Solidária". O período de coleta de dados foi entre os meses de janeiro e setembro de 2009 , quando procuramos compreender o ambiente em que se pretende aplicar a transferência de tecnologias. A troca de saberes demonstra -se fundamental para a efetividade das ações, já que o conhecimento científico não se sustenta num ambiente dominado por tamanha complexidade, obrigando a um exercício permanente de humildade e de reflexão sobre as próprias certezas, havendo a necessidade de um constante diálogo ent re o conhecimento científico e o popular.

Este artigo está estruturado em duas principais partes. Na primeira, são expostos alguns conceitos e compreensões das relações entre ES, comercialização e a idéia de redes. A segunda parte é dedicada a dimensões qu e sintetizam a experiência vivenciada, em que expomos a experiência da "Colomba Solidária", os desafios e as alternativas a questões relativas às políticas públicas de ES e à produção e comercialização desse modelo.

\section{A economia solidária, comercialização e redes}

A socioeconomia solidária, segundo Arruda (2003), pode ser definida como um sistema socioeconômico aberto, fundado nos valores da cooperação e da partilha, da reciprocidade e da solidariedade. Tal sistema é organizado de forma autogestionária a partir das necessidades, desejos e aspirações da pessoa, da comunidade, da sociedade e da espécie. A finalidade maior da socioeconomia é emancipar a capacidade cognitiva e criativa do homem e libertar seu tempo de trabalho das atividades restritas à sobrevivência material. O que elucida o sentido da socioeconomia é uma nova economia, 
cujo objetivo é responder às necessidades sociais e humanas, ou também atender à dupla demanda na reprodução simples (sobrevivência) e na reprodução ampliada da vida (crescente bem estar individual, comunitário e social).

$\mathrm{Na}$ acepção do autor, a terminologia socioeconomia solidária se distingue da economia solidária devido ao seu caráter muito mais social e generalista. De acordo com Arruda (2003), ela apresenta o sentido idêntico à proposta da humano-economia, feita pelo economista tcheco Eugen Loebl (1978): uma economia a serviço do humano. Embora o presente projeto tenha como referência de trabalho o conceito de socioeconomia de Arruda, fundamentaremos a presente discussão, sobret udo, na economia solidária por entender que institucional e teoricamente ela é a forma de socioeconomia mais desenvolvida e adotada e, principalmente, que as iniciativas de economia solidária podem ser incluídas entre a diversidade de experiências abarcada s pela socioeconomia.

A ES surge como modo de produção e distribuição alternativo ao capitalismo, casando o princípio da unidade entre posse e uso dos meios de produção e distribuição. A lógica da ES é a oposição à ditadura do capital e ao poder ilimitado que o direito de propriedade proporciona, excluindo e controlando vidas, além dessas mesmas desigualdades abalarem a própria estrutura democrática em que se baseiam as sociedades modernas, criando-se um mundo polarizado e insustentável.

Os princípios básicos dos núcleos de produção de ES são a priorização da solidariedade à competição, e a preservação dos postos de trabalho como primazia à lucratividade. Os trabalhadores se dispõem a fazer sacrifícios individuais a favor do bem coletivo. Ajuda e a confiança mútuas são condições básicas para o sucesso de qualquer empreendimento dessa natureza, também o são a adesão voluntária aos princípios da solidariedade, da igualdade, da democracia e da responsabilidade. São esses atributos que levam os trabalhadores a penetrar no campo da cultura e da ética.

No que diz respeito aos benefícios do desenvolvimento das iniciativas de ES, Sousa Santos (2002, p. 37) destaca que elas

[...] ampliam a democracia participativa, estendendo o princípio de cidadania à gestão das empresas. Semelhante ampliação da democracia tem efeitos emancipadores evidentes, por cumprir a promessa de eliminação da divisão que impera hoje entre a democracia política, de um lado, e o despotismo econômico do outro. 
As modalidades que compõem a ES são variadas, desde experiências provenientes das bases, como a união de trabalhadores vitimados pelo desemprego, em pequenas unidades produtivas, ou pequenos produtores que se unem para comprar e vender em conjunto, além de diferentes formas de agricultura fa miliar, redes de comércio justo, incubadoras de empresas, clubes de troca e de microcrédito, entre outras.

As organizações de ES apresentam, como uma de suas vantagens, o seu processo de decisão que, em vez de individual, é coletivo, tendendo a ser mais de mocrático e participativo, visto que conta com a experiência de todos os participantes e não fica restrito à imposição de uma minoria. Com isso tende-se a criar um maior comprometimento de todos. Por outro lado, as decisões, por sua natureza democrática, tendem a ser mais lentas, o que muitas vezes pode tornar -se uma barreira a ser trabalhada.

As iniciativas de ES só poderão ser realmente competitivas se atuarem de forma conjunta, garantindo ganhos de escala e integrando -se complementarmente em forma de rede. Ao criarem-se conexões entre diferentes unidades organizacionais, tem -se a possibilidade de criar uma estrutura verticalizada de produção e distribuição, excluindo se atravessadores e agregando-se ganhos de produtividade e escala. Porém, além dessas possíveis melhoras, as redes ainda possuem outros potenciais, nascidos da integração e/ou parceria com centros de pesquisa, assessorias técnico-científicas, centros de formação continuada de trabalhadores (onde os sindicatos têm exercido papel importante em apoio a trabalhadores que assumem o comando de empresas falidas), como também na procura do desenvolvimento de um quadro de especialistas capazes de inovar estando ao mesmo tempo sintonizados com as necessidades do mundo moderno (SINGER, 1998).

Aqui, também a universidade tem um papel estratégico para a ES com o seu potencial para desenvolver conhecimentos e tecnologias apropriadas a esses empreendimentos, algo que estaria mais próximo do que se vem denominando de tecnologia social. O desafio que se apresenta é restringir o uso das tecnologias convencionais e substituí-las por tecnologias sociais. As tecnologias convencionais não são adequadas à inclusão social, seu principal objetivo é maximizar o lucro privado, característica essa que limita a sua eficácia para a inclusão social. Ela maximiza a 
produtividade em relação à mão de obra, ou seja, quanto maior a quantidade utilizando o menor número de funcionários, mais produtiva ela é. Além disso, as tecnologias convencionais geram e são geradas pela concentração econômica e política, pois as altas tecnologias existentes estão no poder de poucos e grandes capitalistas, enquanto os pequenos empresários ficam sempre atrasados, defasados, utilizando técnicas que foram descartadas pelos grandes empreendimentos. Por último, as tecnologias convencionais, em regra, promovem processos produtivos ambientalmente insustentáveis, seja porque não consideram a degradação do meio ambiente como custo, seja porque foram concebidas dentro de uma lógica atrelada ao consumismo.

Quase que por exclusão, tecnologia social é "um conjunto de técnicas, metodologias transformadoras, desenvolvidas e/ou aplicadas na interação com a população e apropriadas por ela, que representam soluções para inclusão social e melhoria das condições de vida." (INSTITUTO DE TECNOLOGIA SOCIAL, 2004, p. 6). Ela deve ser adaptada ao reduzido tamanho físico e financeiro; não discriminatória; liberadora do potencial e da criatividade do produtor direto; orientada para o mercado interno de massa; liberada da difere nciação entre patrão e empregado. E principalmente deve ser competitiva, pois só assim os empreendimentos autogestionários serão viabilizados economicamente e serão uma alternativa real de inclusão social para a população marginalizada. (DAGNINO, 20 04)

As possíveis contribuições das tecnologias convencionais para as tecnologias sociais ainda são um debate aberto e encerram diversos conflitos e dilemas. Não podem ser ignorados fatos como $\mathrm{o}$ de as novas tecnologias convencionais (incorporação da microeletrônica e informática nas máquinas-ferramentas) viabilizarem a produção em escalas cada vez menores (SHIMA, 2006). A questão é em que medida a tecnologia social pode se apropriar desses conhecimentos, quais as precauções, as implicações e os riscos?

A universidade desempenha um papel central na busca de respostas a essas questões. Como Dagnino (2004) defende, para que a tecnologia social vingue, o papel das universidades como geradoras e disseminadoras de tecnologia e conhecimento é essencial. Entretanto, na prática, não são poucas as barreiras a serem superadas para que isso aconteça. Ainda prevalece na universidade uma visão positivista de ciência, segundo 
a qual a ciência se desenvolve por suas próprias leis, e que a única forma de fazer isso é isolada da sociedade.

Outra alternativa à viabilidade das experiências de ES é a sua atuação em ramos específicos, nichos que não necessitem de escala de produção para se viabilizarem, apoiando-se na diferenciação e na customização de produtos e serviços como estratégi a de desenvolvimento local e comunitário.

Singer (1998, p.123) defende a necessidade de algum tipo de mercado, portanto de competição mercadológica, mesmo dentro de um modelo dominado pelos princípios solidários de organização. Segundo o autor, "Será importante que haja várias empresas competindo pelos consumidores em cada ramo de produção, dentro do setor, para que cada uma delas seja estimulada a melhorar a qualidade e baixar os custos "

Singer, no entanto, reforça que essa competição deverá se dar entre semelhantes, e defende a possível necessidade de um mercado protegido, inicialmente, da competição externa, até poder garantir ganhos de eficiência e aprendizado necessários ao enfrentamento do mercado externo.

Singer (2002) defende, ainda, a necessidade do Estado como incentivador dos diferentes modelos de ES, mediante a disponibilização de linhas de crédito especiais e de medidas de desenvolvimento tecnológico, assim como a prioridade de compra dos produtos e serviços das redes de ES de acordo com as nec essidades de abastecimento do Estado. Essas estratégias privilegiadas não devem, entretanto, indefinidamente, a ponto de gerar dependência excessiva e acomodação, mas escalonadas no tempo de forma a garantir um processo de desenvolvimento.

Adicionalmente, as redes podem se beneficiar do apoio oferecido pelas universidades. A academia pode capacitar e instrumentalizar essas iniciativas, garantindo Ihes níveis mais elevados de eficiência e eficácia capazes de consolidar a sua efetivação. Um exemplo disso são as incubadoras de ES (OLIVEIRA; ALVES; PONTELO, 2007).

Além das diferentes modalidades e iniciativas que compreendem o vasto universo das organizações de ES, destaca-se, também, o modelo defendido por Euclides Mance, denominado por ele de Redes de Colaboração Solidária. A concepção da idéia de rede parte do princípio de que núcleos de produção que operam isoladamente tendem a fracassar, pois não conseguem superar a concorrência capitalista. A alternativa das redes 
de colaboração solidária é o trabalho em conjunto, mediante a interligação com movimentos de consumo e produção, sendo de suma importância a verticalização da produção, ou seja, o complemento entre células produtivas: se uma produz determinado bem final, demanda insumos que podem ser produzidos por outra célula, num processo cadenciado.

[...] unidades produtivas que operam isoladamente na Economia Informal tendem a fracassar, cedo ou tarde, pois não conseguem superar a concorrência sob a lógica competitiva do mercado capitalista, seja na eficiência em produzir e distribuir a mercadoria, equilibrando preços baixos com qualidade elevada, ou em produzir subjetividades e agenciar o consumo alienante através de semioses publicitárias. [...] Sob a lógica da rede Economia, entretanto, destaca -se que toda a célula produtiva é, primeiramente, uma célula de consumo e que todas as células da rede interligam -se por movimentos de consumo e produção das diversas células interconectadas (MANCE, 2000, p. 48).

O modelo de ES defendido por Paul Singer assemelha -se às redes de colaboração solidária no tocante aos valores centrais. Porém a diferença entre as duas propostas é evidente. Para começar, Mance (1999) acredita que não há a necessidade de apoio do governo para o desenvolvimento das redes, diferentemente de Sing er que vê no apoio governamental um dos fatores essenciais para o desenvolvimento de qualquer iniciativa que almeje ser uma alternativa em larga escala.

Mance (2000) defende a criação de uma rede paralela à do modelo capitalista, enquanto Singer propõe o desenvolvimento do modelo de ES inserido no sistema capitalista, devendo este ser capaz de evoluir a ponto de superá -lo. Mance não aceita qualquer tipo de concorrência, enquanto Singer aponta a necessidade de competição, como forma de pressão para melhoria de produtos, preços e eficiência, o que não seria conseguido pela simples pressão dos consumidores.

Para Singer (2002), a argumentação de Mance (2000) torna -se frágil por apoiar-se basicamente na simples priorização do consumo solidário, mesmo quando os produtos são de pior qualidade e até mais caros. Outra dificuldade desta iniciativa seria fazer com que a totalidade da produção das cooperativas da rede pudesse ser absorvida pelos seus integrantes, sendo estes, na sua maioria, de classes mais pobres e ha vendo, então, a necessidade de o excedente ser vendido no mercado capitalista não protegido. Além do mais, o modelo que se baseia em um consumo solidário puro limitaria a inovação e a 
atualização, gerando comodismo numa situação inferior e cada vez mais di stante da realidade fora da rede.

As redes de ES se apóiam num outro paradigma, como salienta Marcos Arruda (2003, p. 234): “A lógica do capital é migrar para onde há mais capital e possibilidades de acumulação e de lucro, e não para onde há mais necessid ades humanas a satisfazer". É na busca de satisfazer necessidades e desejos que se apóia a lógica deste modelo de sociedade, o que implica, é certo, num "trabalho cultural para fazer emergir uma solidariedade consciente".

Existe constantemente a tentação de buscar alternativas definitivas, que pressupõem soluções com certezas e programações em excesso, não se levando em conta as ambiguidades e subjetividades próprias da complexidade humana. Deve -se evitar o puritanismo e acreditar na capacidade de criar múl tiplas e variadas possibilidades, num ambiente aberto, diverso e em construção, condizente com a natureza complexa do próprio gênero humano, como concordam Singer (2002) e Sousa Santos (2002).

Acreditamos na intransferível e vital articulação das iniciativ as de economia solidária com o Estado, sendo este um agente privilegiado de empoderamento deste modelo socioeconômico, principalmente em sua fase inicial, avançando nas políticas públicas em prol de soluções emancipadoras. Por via inversa, as organizações de economia solidária podem transformar esse mesmo Estado através da sua lógica organizacional amparada em níveis de participação e democracia superlativos, conseguindo subjugar avanços econômicos a fins sociais, algo que se idealiza para esse mesmo Estado. Por certo, a tarefa não é nada fácil. É preciso prevenir -se contra as armadilhas do "engaiolamento" das demandas solidárias pelas burocracias do Estado, as estruturas de vínculos eleitorais e personalismos, mas, sobretudo contra as próprias restrições impostas pelas afinidades estruturais entre o Estado e a economia capitalista. 0 "sucesso" e a expansão da ES não devem angariar, necessariamente, apenas mais apoio, mas também maior grau de oposição organizada, o que pode induzir a conformismos e retrocessos. As brechas abertas também se fecham. Seja como for, como todo ato político insurgente, a ES é uma aposta em um terreno adverso que nos desafia em nossas conviç̧ões, paciência e criatividade .(SANTOS; BORINELLI, 2010) 
Nos itens seguintes, apresentaremos as propostas em torno do projeto PROSOL e algumas considerações extraídas da experiência acumulada até este momento.

\section{Uma leitura do contexto da Economia Solidária em Londrina: desafios e alternativas}

Neste tópico, discorrer-se-á sobre alguns pontos que sintetizam a experiência do PROSOL em sua primeira fase. Após a exposição de uma atividade integrada de produção econômica, são apresentados e discutidos os desafios e as alternativas a questões relativas às políticas públicas de ES e à produção e comercial ização desse modelo.

\section{A “Operação Colomba Solidária”}

A primeira grande atividade conjunta das instituições e grupos de produção ocorreu na Páscoa de 2009. Foi deliberado, conjuntamente, apenas 45 dias antes da semana da Páscoa, o lançamento de um produto c omemorativo: a Colomba Solidária. A colomba é um bolo no formato de uma pomba que simboliza a paz e, tradicionalmente, é comercializado no país na época da Páscoa.

Embora o prazo fosse muito curto para desenvolvimento e comercialização de um produto, aceitou-se o desafio por entender-se que a finalidade da atividade não era a obtenção satisfatória de produtividade e lucro, mas desenvolver uma experiência na qual fosse possível avaliar o comportamento, capacidade de interação e conflitos entre as instituições envolvidas e entre estas e os núcleos de produção na consecução de um objetivo econômico comum. Tentava-se antecipar futuros desafios institucionais e técnicos para a constituição e operação de uma cooperativa.

Após a aprovação do PROSOL, o CPES delibero u pela criação de uma cooperativa dos grupos de produção incubados por ele. A cooperativa pretende abarcar 20 dos 43 núcleos de produção incubados pelo CPES, cerca de 80 trabalhadores diretamente envolvidos em atividades produtivas dos segmentos de artesan ato, alimentos e confecção.

Após um grande empenho e cooperação dos integrantes do PROSOL, do CPES, da Universidade Tecnológica Federal, de boa parte dos 7 núcleos de produção do segmento 
de alimentos, e, na comercialização, de outros 5 núcleos dos segment os de artesanato e têxtil, os resultados foram bastante satisfatórios.

Num curto espaço de tempo foram desenvolvidas e testadas receitas, embalagens, etiquetas para dois tipos de colombas: uma tradicional, à base de farinha branca, e outra, inédita no mercado, à base de farinha integral, ambas com 500 gramas.

Outras atividades fundamentais realizadas no período foram o treinamento de membros dos núcleos de produção para vendas das colombas, a ampla divulgação dos produtos nos meios de comunicação locais, a preparação de 4 pontos de vendas e a distribuição das colombas solidárias no período de Páscoa.

No total foram produzidas 282 colombas tradicionais e 257 colombas integrais, totalizando 539 colombas. Destas, foram vendidas 285 unidades. A diferença entre produção e vendas deveu-se às perdas, 140 que estragaram antes de serem vendidas devido a problemas na combinação dos ingredientes, à degustação para a divulgação do produto, e uma pequena sobra.

Numa avaliação coletiva, após o encerramento da atividade, constaram-se alguns limites da "Operação Colomba Solidária". Quanto à produção foram identificadas: a) falhas no planejamento da produção, ficando a mesma bem abaixo do estimado, fato que comprometeu seriamente o esforço de divulgação do produto; b) falha s na comunicação entre as instituições. Muitas vezes os dados e as informações não possuíam precisão e fluência necessárias, o que em parte levou ao descumprimento de datas críticas do cronograma.

Quanto às relações institucionais, ficaram evidentes as dif erenças relativas à cultura interna das organizações, à concepção e às expectativas em torno da ES e da cooperativa e ao grau de capacitação das equipes nas questões econômicas, administrativas e mercadológicas.

Como um dos propósitos mais significativos da Colomba Solidária era a integração entre as instituições participantes do projeto, considerou -se que os resultados foram muito satisfatórios no sentido de identificar a cultura de trabalho de cada instituição, além das qualidades e limites de cada uma. O bom relacionamento pessoal entre os integrantes das equipes da UEL e do CPES, durante todo o processo, e o direcionamento das avaliações para a esfera das idéias levaram, não obstante os inevitáveis conflitos, a 
uma busca mais concreta de melhorias para o projeto em andamento. A experiência foi percebida como de grande valia para reavaliar o papel das instituições e das políticas púbicas na ES e definir as futuras coordenadas da intervenção.

No campo produtivo, a muito boa aceitação da Colomba Solidária i ntegral foi um importante indicador de que se pode conceber e produzir produtos competitivos e mais saudáveis e, sobretudo, produtos que estejam mais alinhados aos princípios da ES. Contudo, para se atingir essa meta em escala e continuidade satisfatórias, há que se avaliar, rever e pactuar o papel das políticas públicas na ES.

\section{Aspectos gerais das políticas públicas de Economia Solidária em Londrina}

Até este momento, a experiência da Colomba e a análise do contexto e da ação das frentes públicas de ES permitiram identificar alguns limites e possibilidades das políticas públicas de ES em Londrina. O desempenho e articulação dessas políticas mostraram -se fundamentais para a concepção, implementação e consolidação de uma rede de comercialização de produtos e serviços de ES no município.

É possível afirmar que em nenhum outro momento as condições institucionais foram tão favoráveis à ES na cidade de Londrina. Existem várias fontes de recursos para o financiamento de assessoria e compra de bens, equipamentos e matéria-prima para os grupos de produção, como também vários programas e projetos no âmbito do poder público, municipal, estadual e federal e em universidades, cujo objetivo é o apoio a iniciativas econômicas alternativas urbanas e rurais. Por outro lado, a crise atual do sistema econômico e o maior grau de informação da população a respeito dos problemas sociais, ambientais e das grandes ameaças à saúde e ao futuro das sociedades geram uma potencialmente elevada disposição ou abertura para questionar seus estilos de vida e hábitos de consumo. Esse processo vem ampliando, e muito, a demanda por produtos e serviços da ES. Portanto, a oferta de produtos em quantidade e qualidade viáveis, agregados aos princípios da ES, é o maior desafio da ES.

Contudo outros desafios antecedem este, são aqueles relacionados ao desempenho do arranjo institucional das políticas públicas de apoio à ES na cidade.

Coerente com a idéia de que o maior desafio operacional é a produção de produtos competitivos pela diferenciação soli dária, o setor público deve assumir isso como desafio 
coletivo. E, nessa perspectiva, é importante que se assumam as seguintes premissas gerais para a ES no âmbito local: a) o projeto da ES enfrenta restrições de diversas ordens: políticas, econômicas, institucionais, ideológicas, organizacionais, gerenciais e da própria composição dos núcleos; assim, apenas uma ação planejada e articulada entre as instituições do poder público, os grupos de ES, a universidade e organizações da sociedade civil poderia const ruir um espaço legítimo e potencialmente mais viável do ponto de vista econômico e político; b) a ES deve ser uma real alternativa organizacional, econômica e de desenvolvimento local à economia capitalista; c) o setor público e as universidades têm um papel estratégico e insubstituível de protagonistas neste processo de transformação. Assumir essas premissas implicaria na disposição de enfrentar pelo menos alguns problemas, apresentados a seguir.

Em particular, em uma dimensão institucional, há políticas $p$ úblicas fragmentadas e de baixo impacto econômico, fruto em parte de uma baixa articulação institucional horizontal e vertical, portanto da pouca ou nenhuma sinergia institucional para a ES.

No campo, que se poderia designar de ideológico, não há uma "idé ia força", um conceito estruturante contextualizado e operacional para ES. Não existe ainda consenso local entre atores centrais sobre o escopo e o posicionamento político da ES dentro da economia e da dinâmica local. A concepção econômica da ES ainda é si gnificativamente inspirada na política social compensatória e não em uma economia solidária propriamente. A maior ameaça aqui é de se reproduzir o que Pochmann (2004) denominou de assistencialismo improdutivo,

[...], pois ao operar como um fim em si mesm o [o assistencialismo improdutivo] demonstrou ser insuficiente para oferecer portas de saída emancipatória às angústias do conjunto dos excluídos. Poucas têm sido as experiências de políticas públicas articuladas e integradas a uma estratégia de inclusão soberana e de caminhos associados à autonomia social, política e econômica coletiva (POCHMANN, 2004, p.30).

Quanto à gestão, presencia-se um excesso de amadorismo quanto à gestão estratégica e econômica e do planejamento de mercados e produtos. Outro aspec to importante a destacar é a capacidade restrita de pesquisa, sistematização e processamento de dados e informações estratégicas. Em parte, a defasagem nesse campo reflete-se no fato de que, apesar de existirem duas incubadoras de empreendimentos de 
ES, ainda não se constituiu formalmente nenhuma cooperativa até o momento. Atualmente, há no CPES um grupo de trabalho interinstitucional empenhado em constituir a primeira cooperativa de ES da cidade.

Parece claro, como assinala Singer (2002), que, sem o fortal ecimento e a articulação das políticas e instituições públicas de ES, são bastante reduzidas as possibilidades de construir em Londrina uma ES expressiva. Referenciando -se em Dowbor (2008), pode-se dizer que em Londrina já se dispõe de condições relativame nte satisfatórias para se fazer boas sementeiras, restando preparar um terreno fértil para que essas sementes se desenvolvam. Como fica evidente cada vez mais, essas duas tarefas devem ser construídas de forma sincronizada e articulada institucionalmente. Antes de tudo, porém, precisa-se construir um consenso entre os grupos de produção e os atores estatais sobre o papel do Estado e das políticas públicas de ES, de preferência entendendo-se estes como parceiros e interlocutores privilegiados na tarefa de di namizar o associativismo.(ARAUJO; SILVA, 2005)

Diante desse quadro, parece urgente, para maior efetividade de uma rede de comercialização em Londrina: a) criar e consolidar um espaço de interlocução institucional e entre os núcleos de produção da região; b ) estabelecer um pacto entre os representantes do setor público e os núcleos para a elaboração de um plano estratégico para implantação da ES na cidade; e c) investir na capacitação de agentes de políticas públicas em ES.

É importante registrar que, como já se vem constatando em vários encontros entre atores públicos, cresce o consenso de que a ES vem alcançando e exigindo um novo estágio de organização na cidade. Superados relativamente os limites da falta de recursos, de espaços institucionais e de domí nio conceitual e prático da temática, o novo contexto pede uma maior articulação dos atores para enfrentar barreiras de maior complexidade à ES. Este é o caso da pesquisa e do planejamento de linhas de produtos, suporte tecnológico, organização de cadeias produtivas, construção de uma marca forte e competitiva da ES e estratégias de comercialização. Uma importante decisão tomada recentemente por vários representantes de instituições públicas envolvidas com ES foi elaborar coletivamente a Carta da Economia S olidária de Londrina a fim de num segundo momento, definir ações estratégicas articuladas para consolidar a ES na região. 


\section{Perfis dos produtos da ES de Londrina e a proposta de novas áreas de atuação}

O CPES foi implantado em 2005, como instrumento do Prog rama Municipal de Economia Solidária, para dar sequência ao Programa Londrina Fome Zero. Ele tem como eixo a geração de renda e a capacitação profissional. Suas linhas de ação visam desenvolver as finanças solidárias; a educação para o consumo ético, justo e solidário; a capacitação conceitual, técnica e de gestão dos trabalhadores solidários; a assessória técnica e a implementação de uma rede solidária de produção, comercialização e consumo. O CEPES está incubando e apoiando aproximadamente 45 grupos de pr odução em ES. Os grupos são pequenos, em geral, reúnem de 2 a 5 pessoas. No CPES são atendidos apenas grupos de artesanato, alimento e vestuário. Os vinte grupos mais desenvolvidos, dentre os incubados pelo CPES, receberam a proposta para a fundação de uma cooperativa. São nove grupos de artesanato, nove de alimentação e dois de vestuário. Na produção artesanal destacam -se os trabalhos em crochê, os bordados, as peças de retalhos e de papel reciclado. Em relação aos alimentos, a produção concentra se em pães, bolos, biscoitos, salgados para festas, coffe-break, compotas e geléias e café. No vestuário são produzidas principalmente roupas de malha, como camisetas, blusas de moletom, cuecas, camisolas, pijamas, vestidos e bermudas.

A partir do diagnóstico das a tividades desenvolvidas pelos núcleos de produção de ES incubados pelo CPES, já citados, o PROSOL propôs a organização desses grupos em três grandes segmentos, ou setores de atuação, são eles: alimentos, vestuários e artesanato. O PROSOL também propôs, com base numa pesquisa de mercado, que cada um desses três segmentos escolhesse uma família de produtos como carro-chefe da linha de produtos do segmento. A orientação para essa escolha tem dois objetivos principais: primeiro, obter ganhos de escala na produção, reduzindo custos; segundo, facilitar a identificação do consumidor com uma "marca" característica dos produtos feitos pelos grupos de ES, o que garantiria economias de escopo nas atividades de propaganda e marketing de vendas.

Para atingir o segundo objetivo, o PROSOL orientou que as famílias de produtos destacados como carro-chefe buscassem cumprir todos os princípios estabelecidos pela ES, em especial dois deles. O primeiro, relacionado ao benefício à saúde, e o segundo, relacionado à preocupação com a preservação ambiental. A partir destes preceitos, a 
prioridade seria dada a produtos integrais; de produção orgânica; ao uso de fibras naturais renováveis; e, por fim, a matérias -primas recicladas.

Por último, o PROSOL recomendou aos núcleos de produção que utilizassem a diferenciação de produtos como principal estratégia competitiva, já que tais grupos dificilmente conseguirão competir em preços, visto que os custos são elevados devido à baixa escala de produção. Portanto, os produtos carecem ser selecio nados nos mercados que a teoria microeconômica tradicional denomina de "competição monopolística ${ }^{1 ",}$ que é caracterizado justamente por possuir um número razoavelmente grande de produtores ou vendedores competindo no mercado, com produtos e preços diferenci ados.

No setor de alimentos, a escolha do PROSOL foi sugerir a criação de uma linha de produtos integrais. A experiência da Colomba Pascal inspirou essa opção. Ainda que as vendas das colombas tradicionais tenham sido maiores (o preço da colomba integral foi o dobro da tradicional, devido aos ingredientes e tempo de preparo), houve um grande afluxo de pessoas visitando o CPES durante o período de vendas justamente para conhecer o produto integral, pois não havia nenhum similar no mercado londrinense. Além disso, esse afluxo, provocado pela propaganda da colomba integral e pela sua repercussão na imprensa local, contribuiu relevantemente para o aumento das vendas de outros produtos dos três segmentos.

$\mathrm{Na}$ avaliação pós-venda, consultando-se os compradores da colomba e também aqueles que degustaram o produto no CPES, constatou -se praticamente a unanimidade de opinião dos consumidores sobre o melhor sabor e qualidade do produto integral. Muitos consideram vantajoso pagar um preço um pouco mais elevado para cons umir um produto com maior qualidade e sabor. Ao restante dos núcleos de produção de alimentos, o PROSOL preconiza o desenvolvimento de produtos voltados para a produção com matéria-prima advinda da produção orgânica.

No segmento de vestuário, o PROSOL suge riu a fabricação de produtos voltados a características culturais e locais da região de Londrina, por exemplo, desenvolvendo estampas da fauna e flora da região londrinense. A idéia do PROSOL é que os grupos de vestuário produzam camisetas, bonés e outras peças cuja estampa represente, além da

\footnotetext{
${ }^{1}$ Uma explicação didática para as características e estratégias competitivas da estrutura de mercado de concorrência monopolística pode ser encontrada em MATEUS, A. M.; MATEUS, M. M. Microeconomia: Teoria e Aplicações. Lisboa: Verbo, 2002.
} 
fauna e da flora, pontos turísticos da cidade, atendendo assim um segmento de mercado que não está sendo atendido em Londrina pela economia tradicional, ou seja, a de souvenirs ou de "lembranças" destinadas aos turist as e viajantes que passam pela cidade. Esse nicho de mercado nunca foi explorado em Londrina, talvez porque os munícipes não a consideram como uma cidade turística. Não obstante, Londrina é um pólo universitário e o centro comercial de uma próspera região do Estado do Paraná e do Brasil, o que atrai respectivamente o chamado turismo de eventos e o turismo de negócios. Mas também o turismo de lazer tem um grande potencial a ser explorado, pelo menos no âmbito regional. Em breve será inaugurado na cidade um Jardim Botânico construído pela Secretaria de Estado do Meio Ambiente e Recursos Hídricos do Estado do Paraná (SEMA). Já funcionam outros parques ecológicos na cidade como o Parque Arthur Thomas na área urbana, e os parques Daisaku Ikeda, Mata dos Godói e S alto Apucaraninha na zona rural. Se houver uma política pública voltada para este setor de turismo, que articule a visitação a esses parques com a atividade de gastronomia e hotelaria rural, por exemplo, tais espaços podem ser utilizados também para a dist ribuição e venda dos souvenirs e alimentos produzidos pelos grupos de ES.

O segmento de artesanato também pode se beneficiar da consolidação e contribuir para a consolidação de uma "marca ecológica" para a cidade de Londrina e para a ES, utilizando, no processo de produção, fibras, sementes, madeiras de manejo sustentável e materiais recicláveis. Graças ao trabalho desenvolvido pela articulação da Prefeitura Municipal com diversas ONGs de reciclagem de lixo, Londrina é hoje a cidade brasileira com o maior índice de reciclagem. Entretanto, muito pouco deste material é utilizado pelos grupos de artesanato da ES. O desafio dos grupos de artesanato e das instituições universitárias da cidade é desenvolver novos usos para esses materiais. O poder público municipal deve ampliar o apoio às ONGs de reciclagem, e à sociedade cabe cumprir seu papel de cidadania e separar os produtos recicláveis dos resíduos orgânicos, contribuindo ainda com os benefícios do consumo ambientalmente sustentável.

A história e a teoria econômica apontam, de uma lado, algumas condições muito favoráveis ao projeto local de ES e à proposta do PROSOL e, de outro, dificuldades que devem ser superadas. 
Segundo Walter Tadahiro Shima (2006), o novo paradigma tecnológico mundial, baseado na incorporação da microeletrônica e informática nas máquinas -ferramentas, dotando-as de autonomização e flexibilidade, resultou na "banalização das economias de escala e na viabilização das economias de escopo". Ou seja, viabilizou a produção em escalas cada vez menores. As novas tecnologias reduziram em muito o custo dos equipamentos sofisticados, e eles são oferecidos em diversos tamanhos, para diversas escalas de produção.

No novo paradigma, todas as tecnologias hard [...] estão disponíveis com relativa facilidade e a preços descrentes para todos os produtores, de tal forma que o diferencial competitivo não resulta mais do fato de se usar um ou outro equipamento, como ocorria antes do novo paradigma (SHIMA, 2006, p. 347).

O antigo paradigma a que se refere Shima é o modelo fordista, em que a produção em larga escala era o diferencial competitivo, mas a necessidade de as firmas serem competitivas em mercados menores e de atender aos diversificados gostos dos consumidores levou à pesquisa e ao desenvolvimento do novo paradigma tecnológico. Entretanto o autor alerta que, ao contrário dos equipamentos, no novo paradigma há aspectos que não necessariamente estão disponíveis livremente, como os conhecimentos que geram mudanças e os que não decorrem do aspecto hard. Daí que:

A fonte de competitividade da firma não vem de fora, mas da sua capacidade de encontrar, num sentido mais geral, soluções criativas - como novos processos, diferenciação de produtos e, principalmente, novos arranjos organizacionais e/ou institucionais (SHIMA, 2006, p. 347).

Esse desafio inovativo cabe tanto aos grupos de produção, quanto aos poderes públicos e às universidades envolvidos com a ES. Entretanto, ele esbarra na dificuldade de articulação entre os diversos grupos e poderes envolvidos. Confo rme apontado também por Shima:

Se por um lado a cooperação cria oportunidades de aprendizado e de inovação, por outro, esses novos ganhos podem exigir a renúncia do controle de outras atividades (SHIMA, 2006, p. 357).

Já foi possível perceber que este desafio não será fácil de superar. Na experiência da Colomba Solidária, por exemplo, os grupos de produção não deram prioridade para o 
novo produto. Como vimos, o desenvolvimento de uma linha conjunta e articulada de produtos de ES, como o proposto pelo $\mathrm{PRO} S \mathrm{~L}$, exige, senão a renúncia da produção dos atuais artigos produzidos, pelo menos a mudança de prioridades. Ainda que os grupos de ES solidária dominem razoavelmente a produção de artigos tradicionais, tais mercadorias já estão saturadas no mercado pela produção das empresas capitalistas. Por isso só o desenvolvimento de produtos diferenciados e inovadores pode abrir uma grande janela mercadológica para o crescimento da ES. Isso, naturalmente, não quer dizer que o problema de acesso e adaptação de novas t ecnologias da economia tradicional à ES esteja superado, mas que o horizonte das redes de produção e comercialização de ES pode ser bastante promissor.

\section{Considerações finais}

Em relação à proposta original de montar uma rede de apoio à comercialização de produtos e serviços de socioeconomia, os objetivos do PROSOL vêm sendo relativamente alterados para atender a novas demandas que se consideram estratégicas para a efetivação de uma rede de comercialização. Esse é o caso principalmente do apoio à constituição de uma cooperativa dos núcleos de produção do CPES, requisito fundamental para a formalização desses empreendimentos, e do suporte à melhoria da qualidade dos produtos e à prospecção de nichos de mercado e produtos estratégicos para a atuação da ES em Londrina.

A exposição feita até aqui demonstra que a construção de arranjos institucionais mais favoráveis à efetivação da ES exige intervir num campo extremamente complexo e contraditório. Os obstáculos encontrados nos primeiros momentos do projeto são bastante amenizados diante do alto grau de motivação e comprometimento dos técnicos envolvidos, da boa disponibilidade de recursos e, principalmente, da boa recepção e engajamento dos integrantes dos núcleos de produção. Esse contexto amplia as probabilidades de construção de uma experiência inédita de criação de novos arranjos institucionais e tecnológicos para a viabilização da ES em Londrina, em que pesem os vários conflitos e contradições enfrentados diariamente.

Os conflitos e dificuldades vivenciados ne ssa primeira fase devem ser vistos como desafios a serem superados dentro de uma nova lógica socioeconômica e de convivência 
social, que tem na cultura individualista, autoritária e competitiva o seu maior obstáculo. O exercício de construção de ambientes democráticos, participativos e solidários é ainda experimental, por isso povoado de indefinições e incertezas, mas também capaz de mover paixões de quem se vê empenhado na proposta de construção de um novo amanhã, mais justo, fraterno e sustentável.

É necessário ter sempre em mente que a maior parte dos desafios pessoais e institucionais encontrados é constituídas de embates não apenas "tecnológicos" ou mercadológicos, mas políticos e ideológicos. Como seria de esperar, são embates inevitáveis para um projeto contra-hegemônico como se pretende a ES, em sua busca por um modelo econômico social e ambientalmente alternativo ao capitalismo. De qualquer forma, essa busca dá-se hoje em um terreno relativamente aberto à criatividade, à inovação e à determinação na construção de novos saberes, tecnologias e formas de organização social e produtiva.

A avaliação geral feita até este momento permite afirmar que Londrina, a exemplo de outras regiões do país e do mundo, em que pesem todos os desafios apontados, possui um grande potencial para a conquista e a consolidação de importantes avanços na construção de arranjos institucionais de apoio à produção e à comercialização de produtos e serviços da ES.

\section{Referências}

ARAÚJO, H. E.; SILVA, F. A. B. Economia solidária: um novo paradigma de política pública? notas técnicas. mercado de trabalho. Conjuntura e Análise, Rio de Janeiro, n. 28, set. 2005.

ARRUDA, M. Socioeconomia solidária. In: CATTANI, A. D. (Org .). Outra economia. Porto Alegre: Veraz, 2003.

DAGNINO. R. A tecnologia social e seus desafios. In: FUNDAÇÃO BANCO DO BRASIL. Tecnologia Social: uma estratégia para o desenvolvimento. Rio de Janeiro, 2004.

DOWBOR, L. A organização de iniciativas locais. In: . Desafios da economia

Solidária. São Paulo: Editora e Livra ria Instituto Paulo Freire, 2008.

INSTITUTO DE TECNOLOGIA SOCIAL. Reflexões sobre a construção do conceito de tecnologia social. 2004. Disponível em:

<http://www.itsbrasil.org.br/pages/12/Reflexoes_construcao_conceito_TS.pdf >. Acesso em: 20 maiO 2009. 
MANCE, E. A. A Revolução das Redes: a colaboração solidária como alternativa pós capitalista à globalização atual. Petropolis: Vozes, 2000.

MATEUS, A. M; MATEUS, M. M. Microeconomia: teoria e aplicações. Lisboa: Verbo, 2002.

SHIMA, W. T. Economia de redes e inovação. In: PELAEZ, V.; SZMRECSÁNYI, T. (Org.). Economia da inovação tecnológica. São Paulo: Hucitecl, 2006.

OLIVEIRA, B. A. M; ALVES, F. K. N.; PONTELO, T. C. As contribuições das incubadoras tecnológicas de cooperativas populares para o desenvolviment o da economia solidária e para a construção de um novo modelo de extensão universitária . In: ABREU, J. C. (Org.). Cooperativismo popular e redes solidárias. São Paulo: All Print, 2007. p. 121-132.

POCHMANN, M. Economia Solidária no Brasil: possibilidades e limites: notas técnicas.mercado de trabalho. Conjuntura e Análise, Rio de Janeiro, n. 24, ago. 2004.

Londrina. Prefeitura Municipal. Perfil do Município de Londrina (2008). Londrina: PML/SMP, 2008.

SANTOS, B. S. (Org.). Produzir para viver: os caminhos da produção não capitalista. Rio de Janeiro: Civilização Brasileira, 2002.

SANTOS, L. M. L; BORINELLI, B. Socioeconomia Solidária: propostas e perspectivas. Londrina, 2010. Mimeo.

SINGER, P. Globalização e desemprego: diagnóstico e alternativas. São Paulo: Contexto, 1998.

. Introdução à economia solidária. São Paulo: Fundação Perseu Abramo, 2002. 